\title{
DIRECT RECORDING OF SOUNDS AND PRESSURES WITHIN THE HEART
}

\author{
BY \\ D. W. BARRITT AND D. H. DAVIES \\ From the Cardiac Department, Bristol Royal Hospital, Bristol \\ Received October 22, 1962
}

Pressure waves and vibrations in the heart and great vessels may be conducted to a manometer outside the body by a system of tubing filled with fluid. More than a metre of tubing is usually needed as the circulation is entered at an arm vein. Any such system has the following defects.

1. Delay in the transmission of the low frequency pressure waves to the manometer: the delay will vary slightly with different tubes and with the temperature and density of the fluid within.

2. Unwanted vibrations set up along the length of the tubing as its sides are set in motion by the heart chambers that it traverses.

3. Smoothing-out of the pressure waves or overshoot is almost unavoidable as a result of the elasticity of the tubing and the inertia of the fluid.

4. The high frequency, low amplitude vibrations that constitute audible sounds and murmurs are so poorly conducted that no satisfactory sound record can be made.

Elimination of the long fluid column by the use of a miniature manometer introduced into the heart may overcome all these difficulties. Such a manometer is now available and Soulié and his team have reported their extensive use of the Allard-Laurens micromanometer (Soulié et al., 1961). The present paper reports our preliminary experience with this instrument.

\section{The Apparatus}

Manufactured by Telco of Paris the micromanometer (Fig. 1) is an inductance type transducer mounted at the tip of a standard no. 8 double lumen catheter. A magnetic core is held between two thin

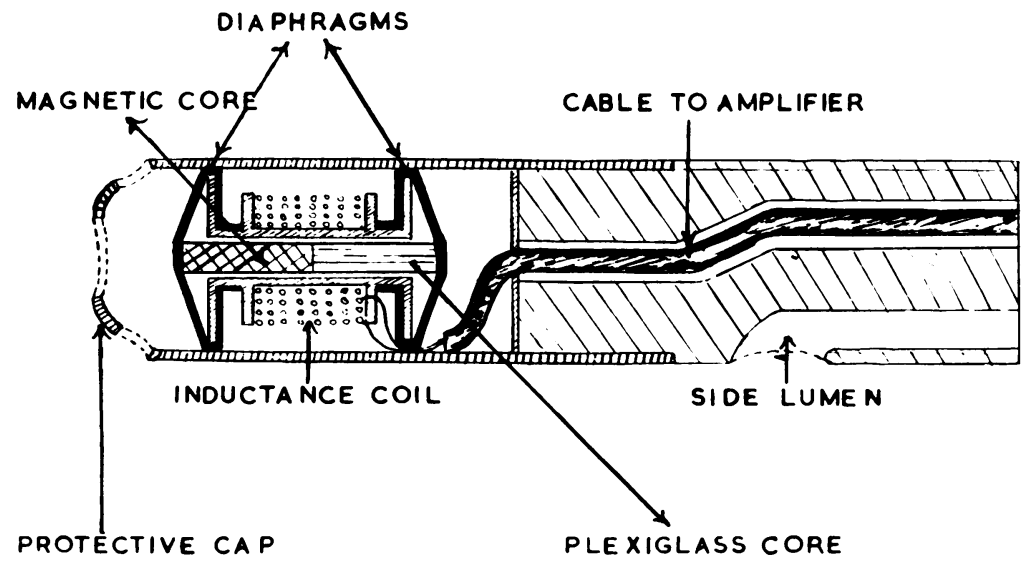

FIG. 1.-Micromanometer. 


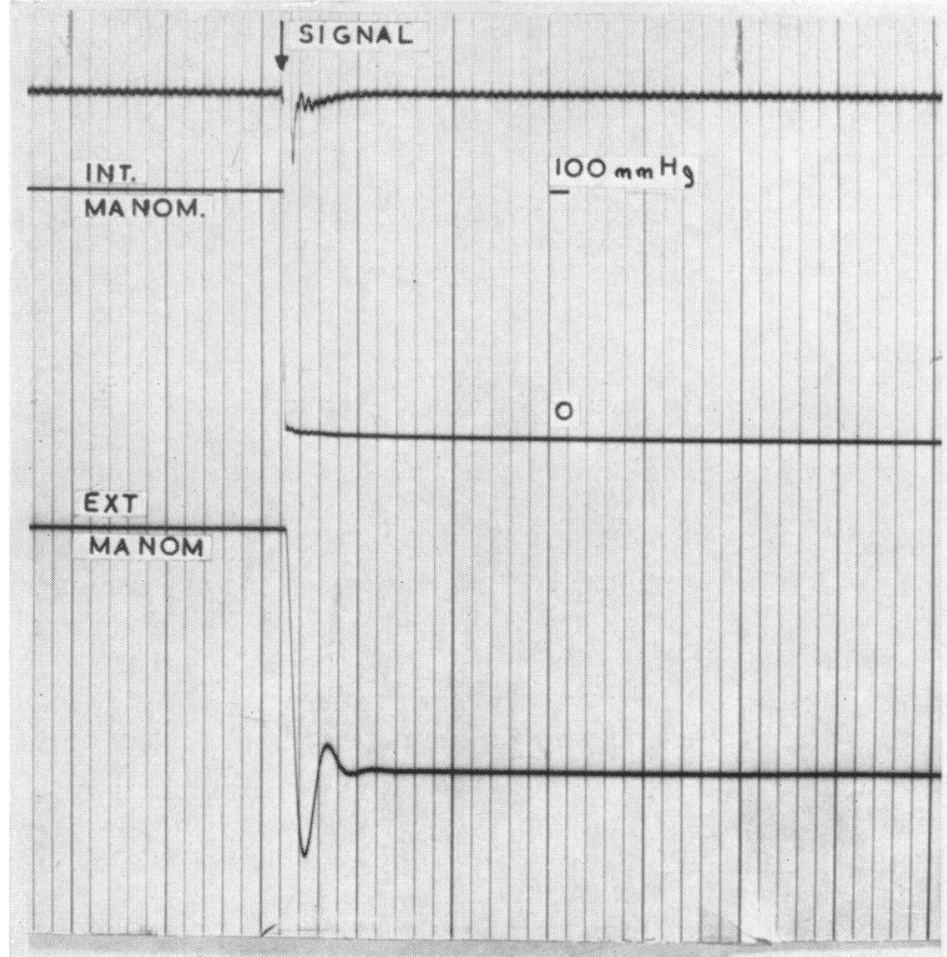

FIG. 2.-Tiansmission delay curve.

diaphragms and moves axially with pressure change. Its movement modifies the inductance of a coil around it. The signals are amplified and low frequency vibrations give the pressure waves and high frequencies record sounds. The sound channel accepts frequencies of the order of 30 to 2000 cycles per second. Thus, sounds and pressures are recorded separately and simultaneously from the catheter tip with no transmission delay. The second lumen of the catheter allows blood sampling and a standard pressure

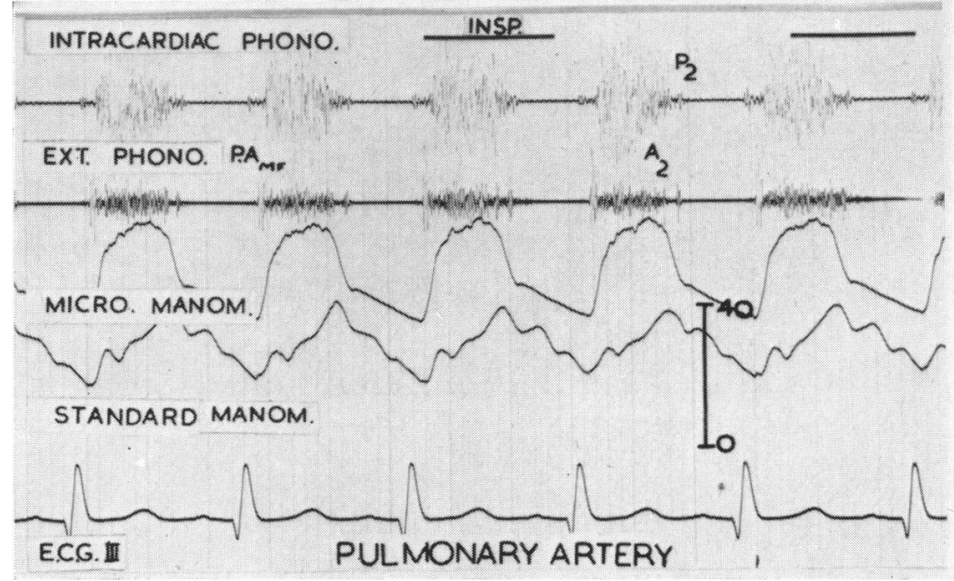

Fig. 3.-Pulmonary valvular stenosis with ventricular septal defect. 
recording through the side hole. Sounds have been recorded at a paper speed of $80 \mathrm{~mm}$. per second using N.E.P. galvanometers and camera. The internal manometer is calibrated by superimposing the pressure curve upon that from a standard external manometer (N.E.P.) on an oscilloscope. The pressure range has always been taken from the standard pressure record and calibrated against a mercury manometer after each recording.

A comparison of the transmission delay of the two manometers using a method as described by Norman (1958) is shown in Fig. 2. After inserting the catheter into a glass cylinder with a thin rubber covering a pressure of $100 \mathrm{~mm}$. Hg has been applied. Rupture of the covering allows the pressure to fall rapidly to zero. There is no measurable delay in the onset of pressure change recorded by the internal manometer and the whole range is registered in less than $0.01 \mathrm{sec}$. The initial fall in pressure registered by the standard manometer at the end of the saline column is slightly delayed and the full range of pressure fall occupies $0.04 \mathrm{sec}$. No artificial damping has been applied and motion artefacts are very evident.

Passage of Catheter. Over 60 patients have been studied, all but 4 having congenital heart disease. Although the catheter is somewhat rigid and has no curve at the tip, little difficulty has been experienced in gaining the pulmonary trunk even in children as young as 3 years. Only once has the catheter been passed from the saphenous vein and on this occasion the right ventricle could not be entered.

The time taken to obtain good records has been an important factor. In consequence our only additional techniques have been measurement of pulmonary blood flow, careful sampling of blood for oxygen saturation, and angiocardiography, when called for.

\section{RESULTS}

Pressure Curves. Freedom of the pressure curves from unwanted vibrations has been a very satisfactory feature of the records from the pulmonary trunk. In pulmonary stenosis (Fig. 3) and atrial septal defect (Fig. 4) the superiority of the internal manometer tracing has been particularly

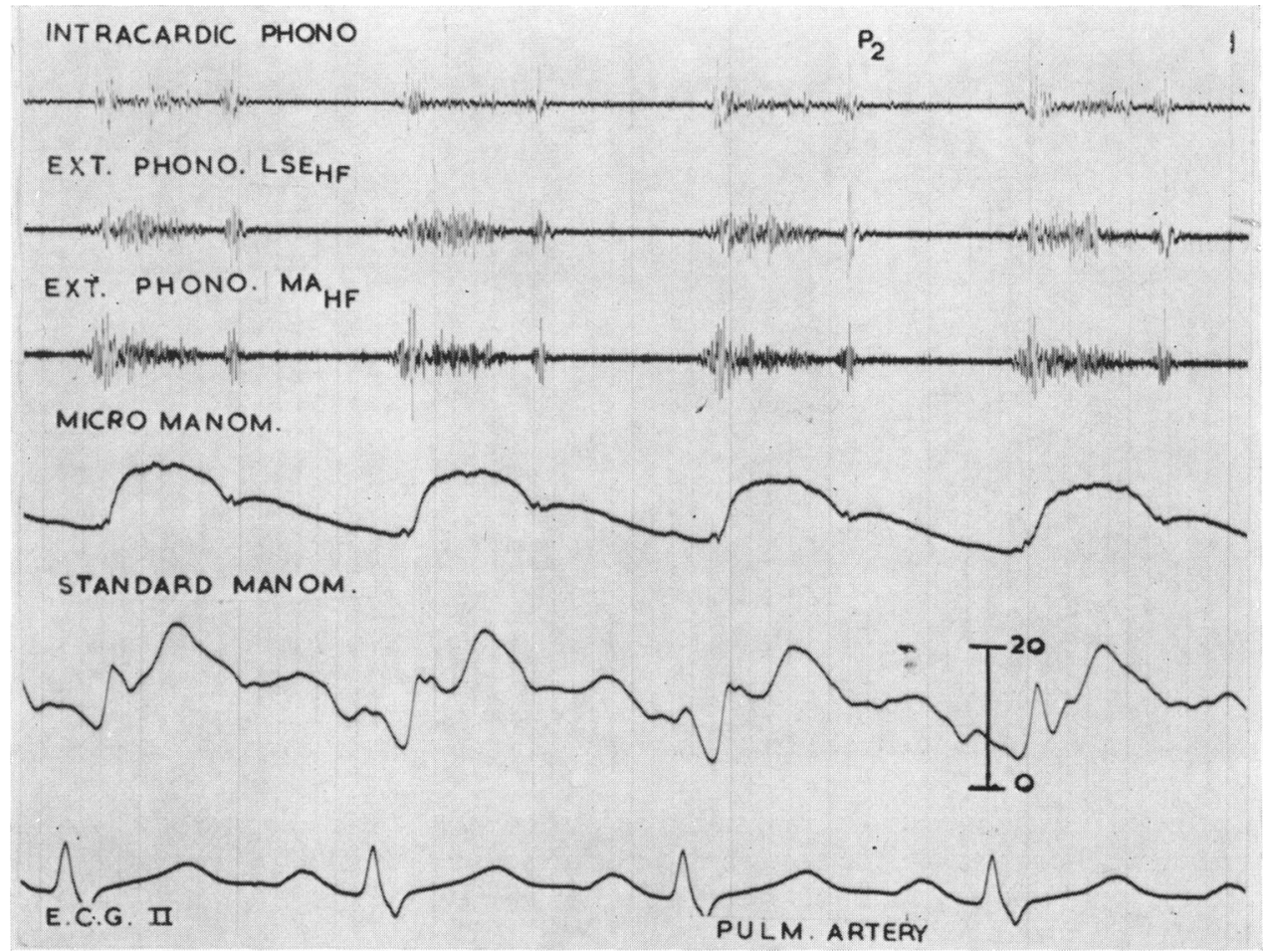

Fig. 4.-Recordings from a case with atrial septal defect. 
evident. In these conditions a low pulmonary arterial pressure and vigorous right ventricular movement often spoils the standard pressure curve. A clear record of the pulmonary dicrotic notch allows pulmonary valve closure to be timed with confidence and the steadiness of the falling pressure wave during diastole makes possible a worth-while analysis of pulmonary vascular compliance (Shaw, 1961).

Pressure tracings from the ventricles are free from the overshoot on the upstroke and downstroke that is so commonly seen in catheter records (Fig. 5 and 6). The onset of rise in pressure in the ventricle can be timed accurately and the relation of pressure changes to valve movements more readily studied.

The rapid low pressure changes in the atria are also damped by a long fluid column. Atrial tracings from the internal transducer are characterized by a very sharp $x$ descent usually synchronous with the atrioventricular valve closure (Fig. 7).

Heart Sounds and Murmurs. Heart sounds and murmurs are localized more exactly with an internal transducer than with microphones on the chest wall. In the right side of the heart, for instance, sounds and murmurs can be localized by passing the transducer back and forth in the area of maximal vibrations until the site of origin of the sound is clear. Some difficulty results from

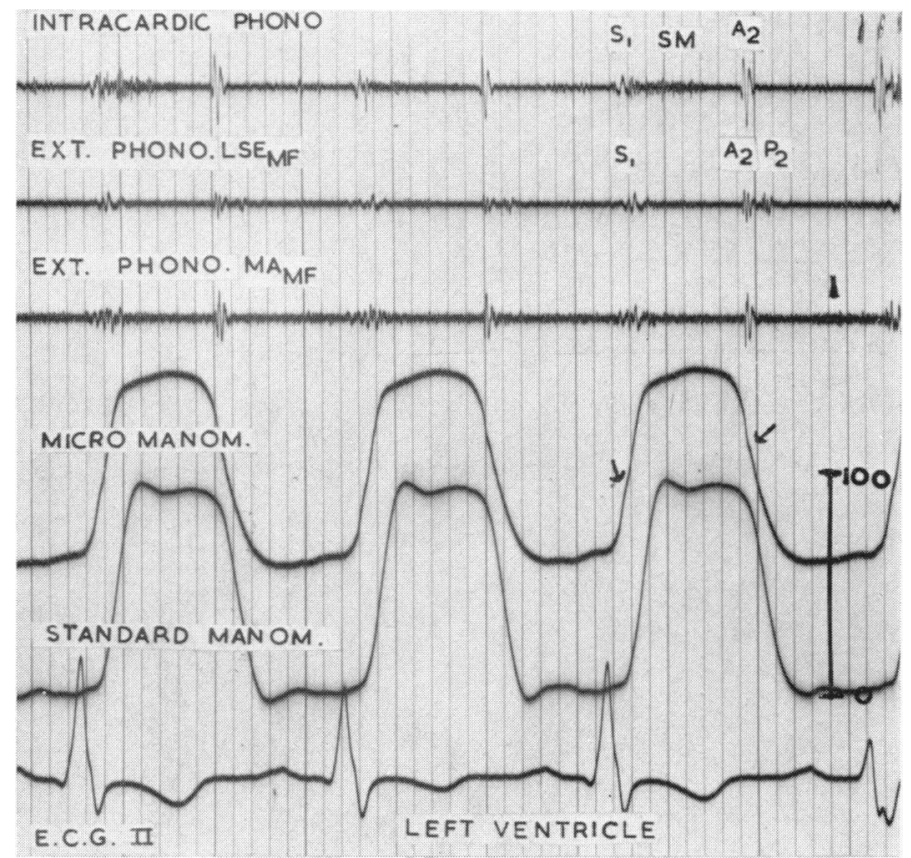

Fig. 5.-Atrial septal defect. The arrows at the ventricular pressure curve indicate the moment of valve movement.

the fact that more intense sounds are transmitted across the cardiac septa and recorded on the other side of the heart. For instance, the aortic valve closure sound is usually well recorded in the right ventricle (Fig. 8) and a loud pulmonary ejection murmur is also well recorded in the superior vena cava and in the left atrium (Fig. 9).

Almost all sounds and murmurs have been recorded best when the transducer was placed distal to the site of origin of the sound. The sounds have been carried forwards in the blood stream with 

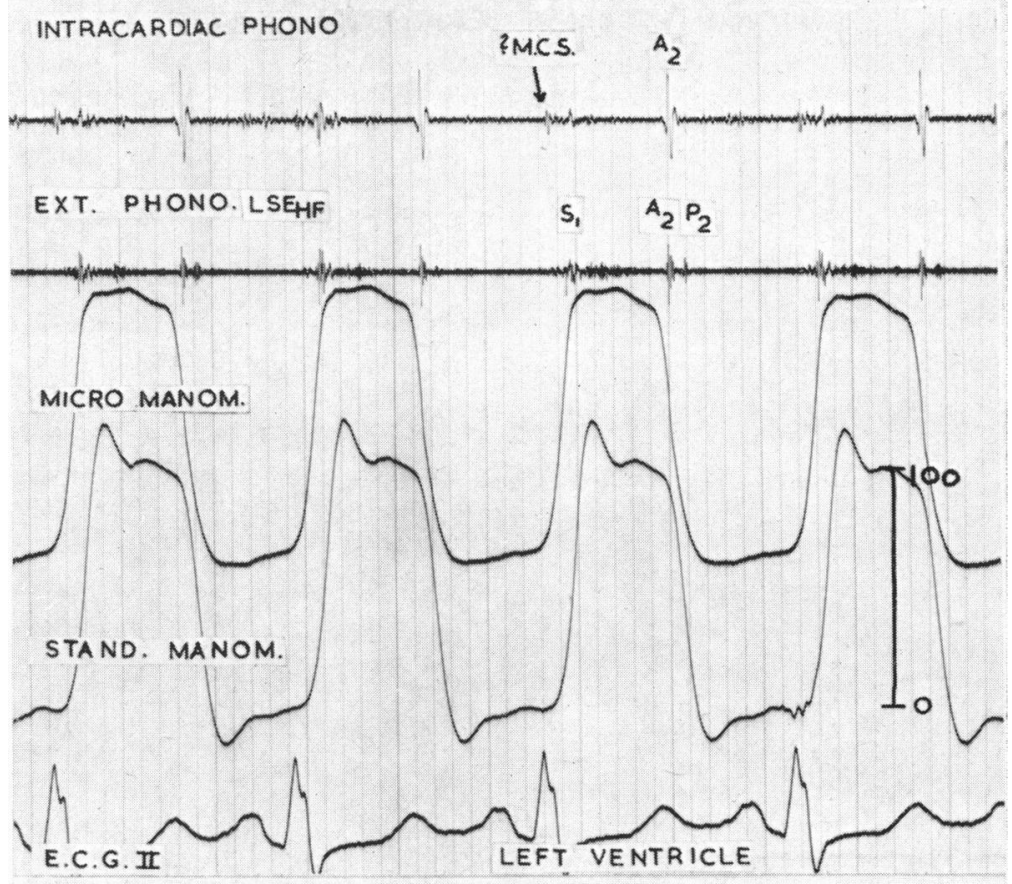

FIG. 6.-Atrial septal defect.

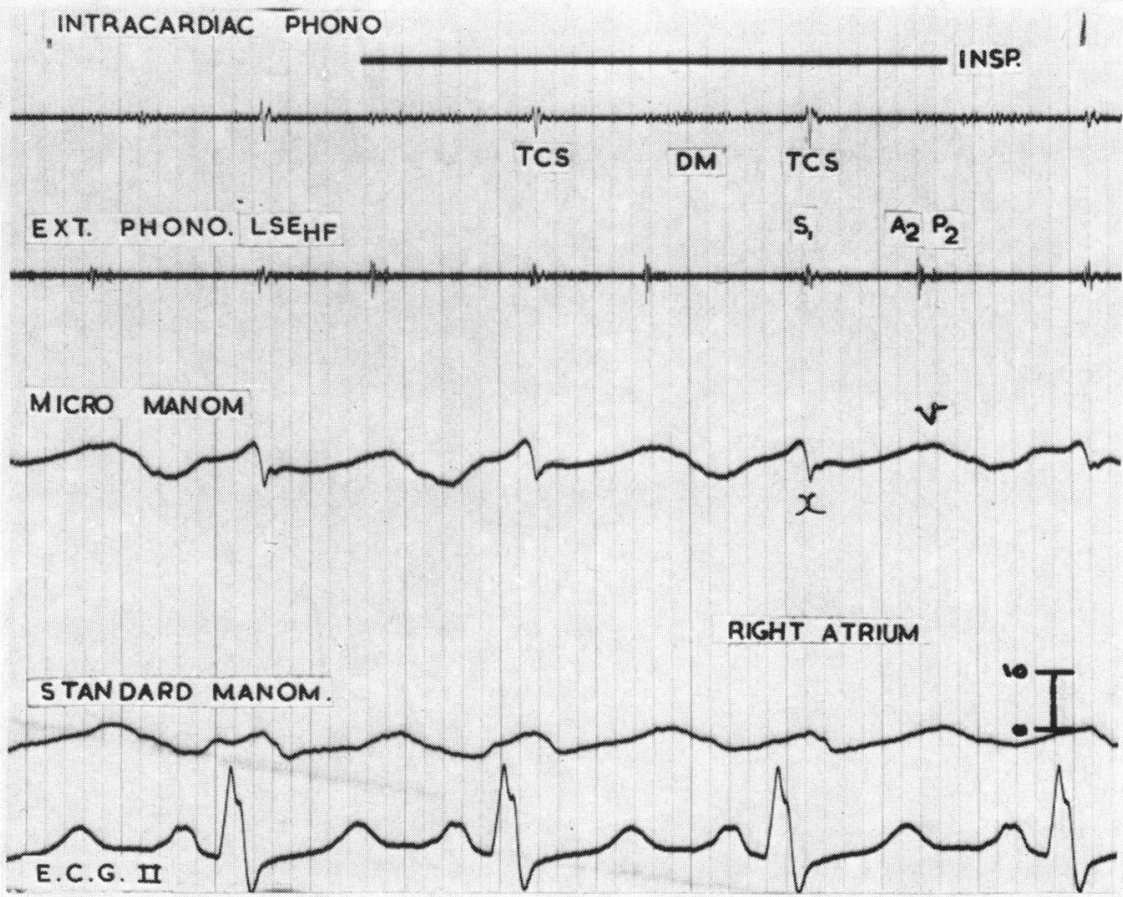

FIG. 7.-Atrial septal defect. 


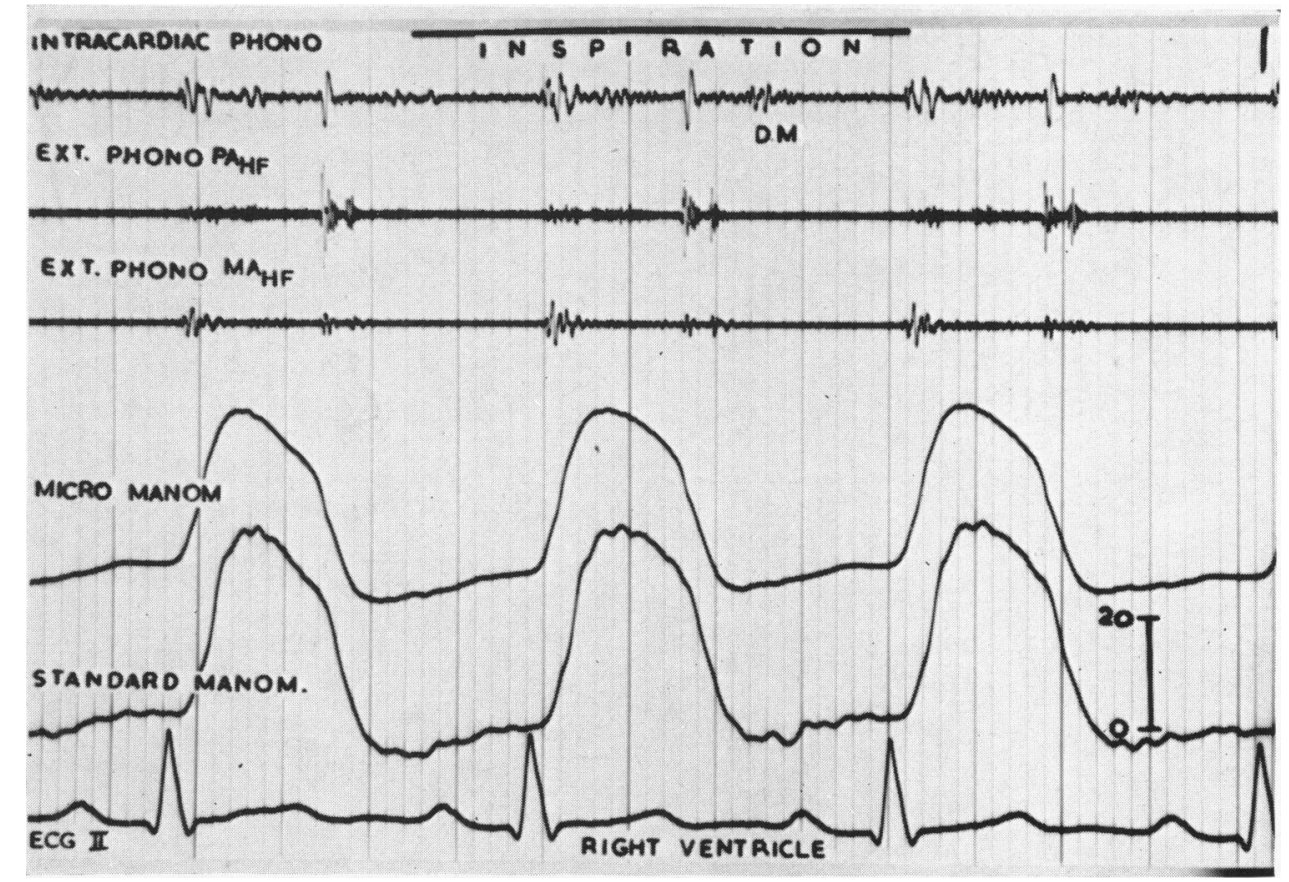

FIG. 8.-Atrial septal defect. The aortic closure sound is clearly recorded in the right ventricle.

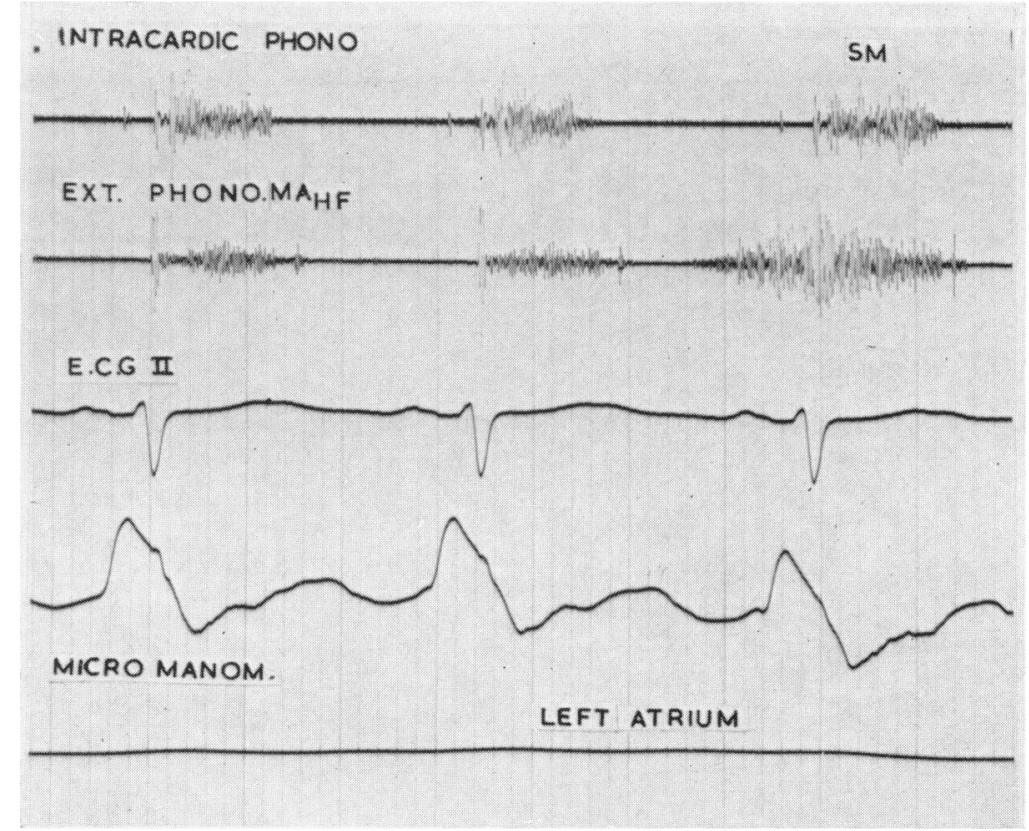

Fig. 9.-The ejection murmur of pulmonary valvular stenosis is clearly recorded in the left atrium. 


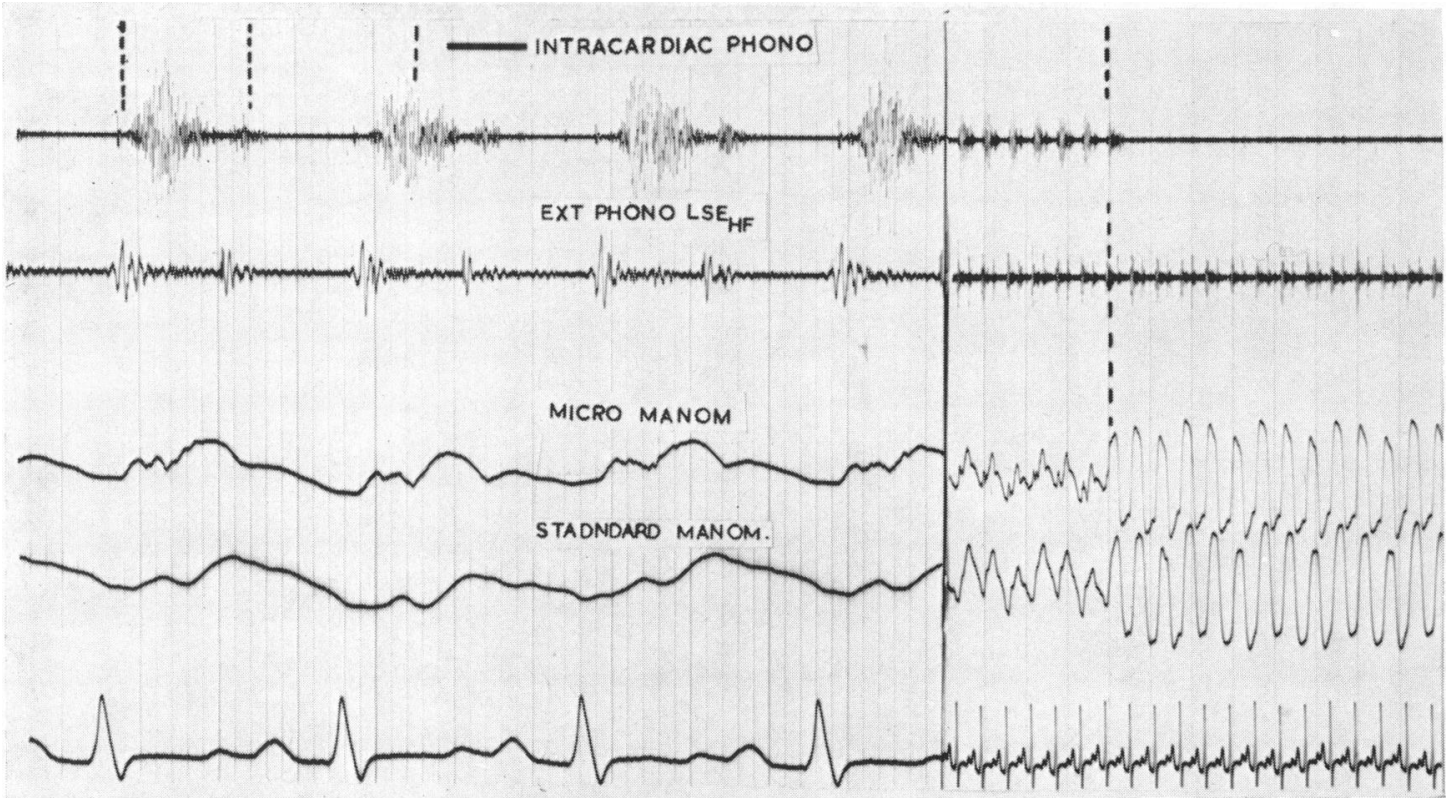

Fig. 10.-Withdrawal tracing P.A. to R.V. in atrial septal defect. The ejection murmur is lost as the manometer enters the right ventricle.

little attenuation. The ejection murmur of pulmonary stenosis or of atrial septal defect is well recorded in the branches of the pulmonary trunk and is usually intensified as the transducer is withdrawn towards the pulmonary valve. As the catheter tip passes backwards below the valve to enter the right ventricle the murmur is at once attenuated or lost (Fig. 10).

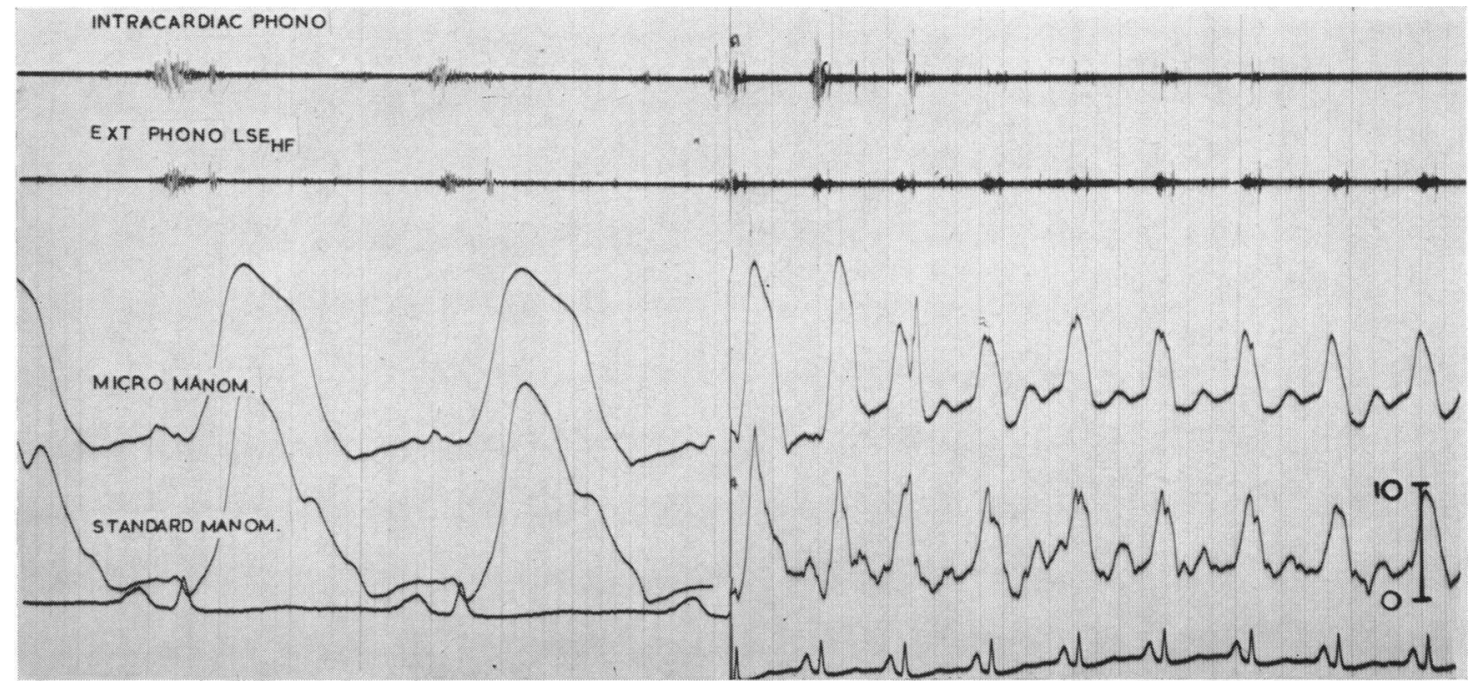

Fig. 11.-Tricuspid stenosis. The atrial systolic murmur is recorded clearly in the right ventricle and lost as the manometer is withdrawn into the right atrium. 


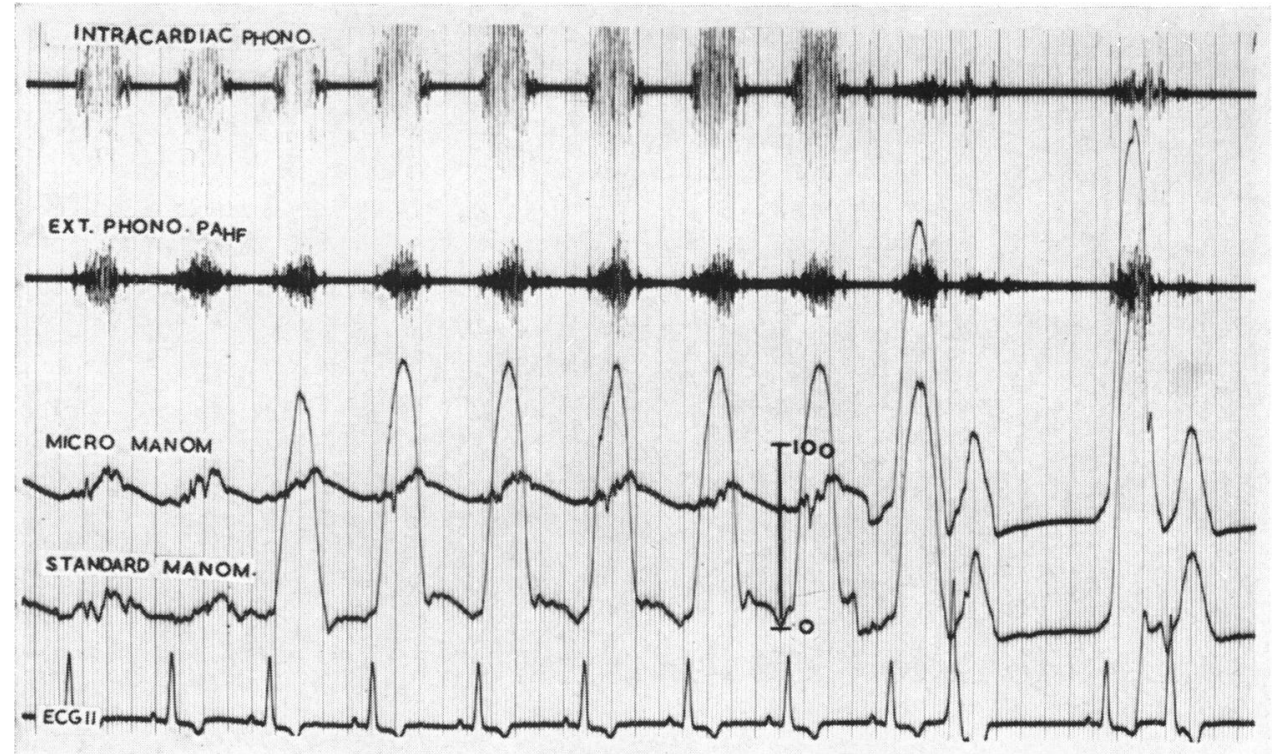

(A)

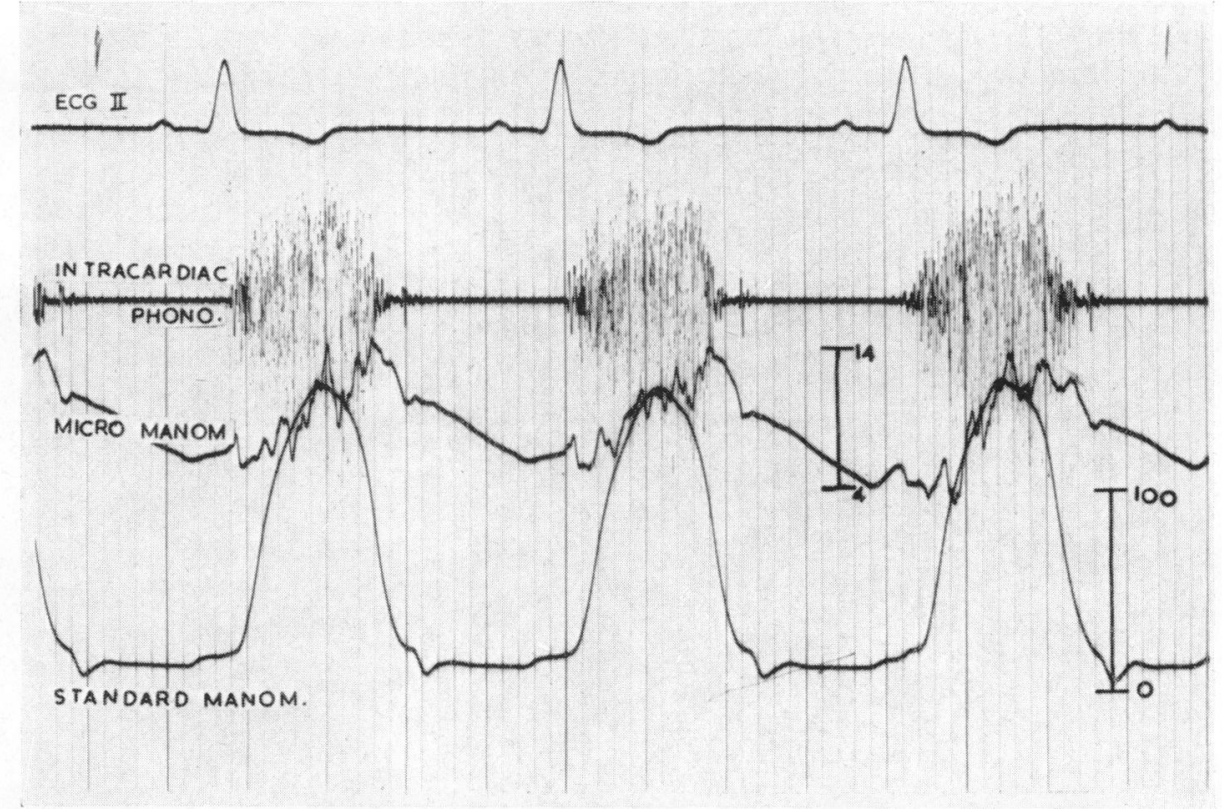

(B)

Fig. 12.-(A) Pulmonary valvular stenosis withdrawal tracing. (B) Record with the tip of the manometer above the stenosis and the side hole below the valve. 
Similarly, the murmur of patent ductus arteriosus is recorded well throughout the pulmonary arteries but is not seen in the aortic record until the transducer is entering the ductus.

Right atrial gallop sounds and atrial systolic murmurs (Fig. 11) are well seen in the lower part of the right ventricle.

Pulmonary valvular, or infundibular, stenosis may be distinguished with more confidence when a sound record is added to the withdrawal tracing. When the stenosis is valvular the standard pressure record from the side hole first shows the pressure gradient, and the site of the valve may be accurately shown with the diaphragm of the intracardiac manometer above the valve and the side hole below (Fig. 12). Here, the ejection murmur is intense. As the diaphragm passes below the valve an abrupt rise in pressure occurs and the systolic murmur ceases with the first beat. In the case of an infundibular stenosis (Fig. 13) there is no pressure gradient across the valve and no change in the murmur as the tip enters the infundibular chamber. Below the stenosis the harsh ejection murmur is replaced at once by the less intense murmur of ventricular septal defect, which begins a little earlier and has no accentuation in mid systole. Recordings from the chest wall resemble the pulmonary ejection murmur which is the louder of the two.

Murmurs produced by ruptured sinus of Valsalva allow the exact site of the rupture to be identified. The record overleaf (Fig. 14) illustrates the localization of such a fistula opening into the outflow tract of the right ventricle.

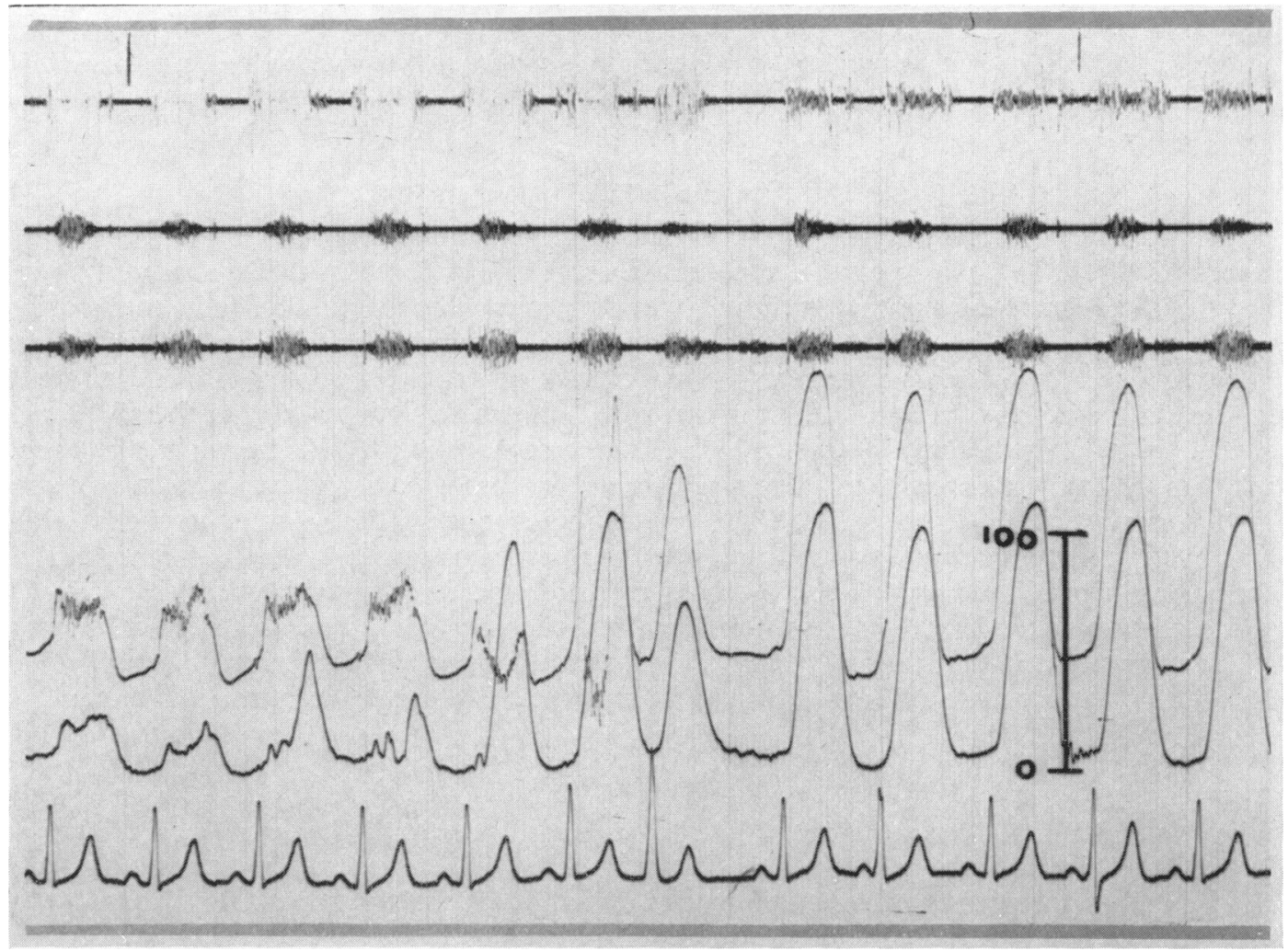

FIG. 13.-Ventricular septal defect and infundibular pulmonary stenosis. Withdrawal tracing from the infundibular chamber to the main right ventricle. The harsh murmur changes in character as the manometer passes below the stenosis. 


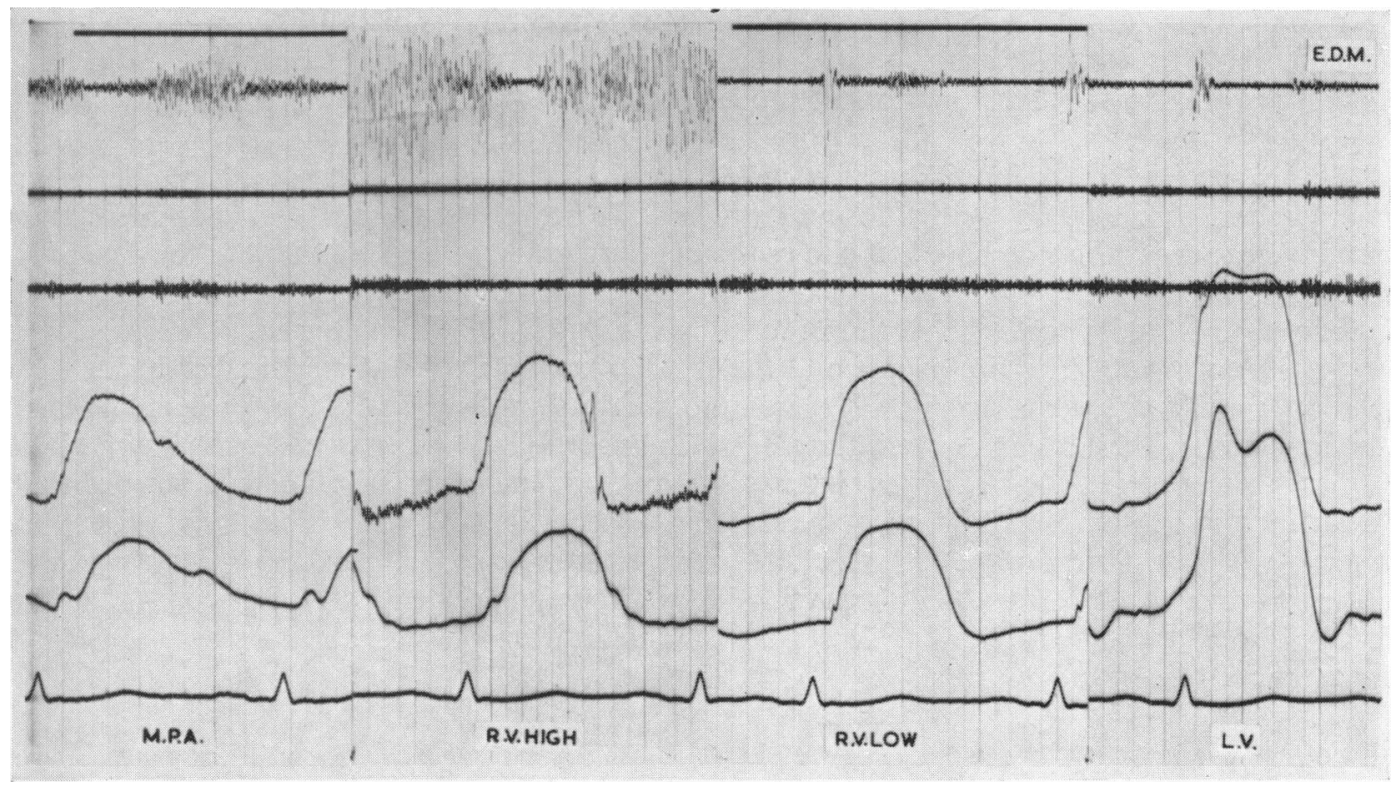

Fig. 14.-Ruptured sinus of Valsalva into the outflow tract of the right ventricle. As the catheter is withdrawn from the right ventricular outflow tract to the lower part of the ventricle the very harsh murmur is lost. In the left ventricle the murmur of aortic regurgitation is seen.

\section{DisCussion}

Intracardiac sound records have been made by at least three methods. Yamakawa and his colleagues (1954) in Tokyo used a capacitance method. Lewis et al. (1957, 1959 a and b) employed a catheter with activated barium titanate at its tip as their microphone. Both of these methods have the great disadvantage that the pressure tracing to which the sounds are referred is recorded outside the body. The Allard-Laurens intracardiac manometer on which this paper is based allows the simultaneous recording of sounds and pressures within the heart. Its great value, therefore, is that exact timing of the relation of sounds and pressures can be studied. Furthermore, the pressure records are relatively free from the motion artefacts and damping that mar previous catheter tracings.

Two reservations need to be made. The localization of sounds and murmurs by the transducer is incomplete in that intense sounds are transmitted fairly widely through the heart and may be found on the record in an adjacent chamber. On the other hand, a sound may be lost from the record if the transducer is moved a short distance within the same chamber. There is no certainty, therefore, that a sound present in any particular heart chamber will appear on the tracing. Critical study is needed or the interpretation of the record may be incorrect. At times, doubt will still remain.

\section{SUMMARY}

The Allard-Laurens intracardiac manometer has been found to give clear records of pressures and sounds within the heart. Elimination of transmission delay and the damping effect of a long saline column on the pressure tracing allow a more confident assessment of the relation between pressure change and heart sounds and murmurs. 


\section{REFERENCES}

Lewis, D. H., Deitz, G. W., Wallace, J. D., and Brown, J. R. (1957). Intracardiac phonocardiography in man. Circulation, 16, 764.

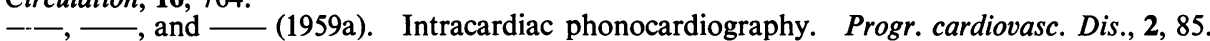

-, Ertugrul, A., Deitz, G. W., Wallace, J. D., Brown, J. R., and Moghadam, A. (1959b). Intracardiac phonocardiography in the diagnosis of congenital heart disease. Pediatrics, 23, 837 .

Norman, J. (1958). Transmission delay times in catheter/manometer systems. J. Soc. Cardiolog. Technicians, 3, 197.

Shaw, D. (1961). Pulmonary artery pressure wave analysis: a method of assessing pulmonary vascular elastic resistance. Brit. Heart J., 23, 461.

Soulié, P., Baculard, P., Bouchard, F., Cornu, C., Laurens, P., and Wolff, F. (1961). Intracardiac sound. Arch. Mal. Cour, Suppl. 1.

Yamakawa, K., Shionoya, Y., Kitamura, K., Nagai, T., Yamamoto, T., and Ohta, S. (1954). Intracardiac phonocardiography. Amer. Heart J., 47, 424. 